\title{
A review of visual impairment
}

\section{Authors:}

Shivani Naipal ${ }^{1}$ (D)

Nishanee Rampersad ${ }^{1}$

\section{Affiliations:}

${ }^{1}$ Discipline of Optometry,

University of KwaZulu-Natal,

South Africa

Corresponding author:

Shivani Naipal,

shivaninaipal@gmail.com

Dates:

Received: 09 Mar. 2017

Accepted: 18 July 2017

Published: 26 Jan. 2018

How to cite this article:

Naipal S, Rampersad N. A

review of visual impairment.

Afr Vision Eye Health.

2018;77(1), a393. https://doi.

org/10.4102/aveh.v77i1.393

\section{Copyright:}

(C) 2018. The Author(s).

Licensee: AOSIS. This work

is licensed under the

Creative Commons

Attribution License.
Visual impairment (VI), a global concern that is likely to escalate with prolonged life expectancies, has gained increasing attention in the realm of eye care. The purpose of this article is to highlight the different aspects of VI, including its definition and characteristics, prevalence, causes and implications. The importance of rehabilitation in individuals with VI is also discussed.

\section{Introduction}

\section{Definition and characteristics of visual impairment}

Visual impairment (VI) is a condition of reduced visual performance that cannot be remedied by refractive correction (spectacles or contact lenses), surgery or medical methods. ${ }^{1}$ Consequently, it results in functional limitations of the visual system that may be characterised by irreversible vision loss, restricted visual field and decreased contrast sensitivity, increased sensitivity to glare as well as decreased ability to perform activities of daily living, such as reading or writing. ${ }^{2}$

Corn and Lusk ${ }^{3}$ affirm that individuals with VI have measurable vision, yet experience difficulties accomplishing visual tasks even with the use of refractive correction. Furthermore, these individuals are sometimes capable of enhancing their abilities to accomplish visual tasks with the use of compensatory low vision aids and/or environmental adjustments. ${ }^{3}$ This description of VI is useful because it considers that individuals with VI may not always display predictable clinical changes in visual function and that changes in functional vision may not always correlate to measurable changes in clinical findings. ${ }^{3}$

In 1992, the World Health Organization (WHO) added a functional dimension to the definition of VI. ${ }^{4}$ This definition is stated as:

a person with low vision is one who has impairment of visual functioning even after treatment and/or standard refractive correction, and has VA of less than 6/18 to light perception, or a visual field of less than 10 degrees from the point of fixation, but who uses, or is potentially able to use, vision for the planning and/or execution of a task. (p. 18) (,5 $^{4}$

This definition refers to the visual acuity (VA) of the better eye with the best possible refractive correction.

According to the International Classification of Diseases, 10th revision (ICD-10), VI may be classified into four levels, namely mild or no VI, moderate VI, severe VI and blindness. ${ }^{6}$ Moderate and severe VI are collectively categorised as VA of less than $6 / 18$, but equal to or better than $6 / 120$ in the better eye with the best refractive correction (Table 1). ${ }^{4,6}$ When the extent of the visual field is considered, an individual with a visual field radius of no greater than 10 degrees around the central point of fixation in the better eye is placed in the third category (blindness). ${ }^{6}$

\section{Prevalence of visual impairment}

Few studies have reported on the prevalence of VI. ${ }^{7,8,9,10}$ More than $90 \%$ of individuals with VI live in developing countries. This geographical disparity may be attributed to a higher prevalence of conditions related to poverty or environmental conditions and poor access to health care services in developing countries. ${ }^{4,7,11}$ In terms of gender, women are at a higher risk of VI because of longer life expectancies and lack of access to health care services especially in rural areas. ${ }^{4}$ Furthermore, the global prevalence of blindness is greater in women than in men. ${ }^{12}$ Interestingly, Stevens et al. ${ }^{12}$ found that for blindness, this gender disparity is highest in high-income regions and lowest in Sub-Saharan Africa. The authors hypothesised that this low gender disparity in Sub-Saharan Africa may be because of onchocerciasis, which is more prevalent in men than women in endemic African regions. 
The prevalence of VI varies depending on whether presenting vision or best-corrected vision is reported. ${ }^{13}$ In 2002, it was estimated that with best-corrected vision there were 161 million individuals with VI globally. ${ }^{9}$ However, when the prevalence of uncorrected refractive error was included, this value increased substantially to 314 million individuals with VI. ${ }^{14}$ This implies that an additional 153 million individuals were visually impaired from uncorrected refractive error alone. ${ }^{14}$

The literature reports that there might be a decrease in the prevalence of VI (Table 2). ${ }^{9,10,11,12,13,14,15,16}$ By 2010, there was an overall decline worldwide of approximately $10 \%$ in the total number of individuals with VI from 314 million to 285 million, of which an estimated $6.6 \%$ were children younger than 14 years. ${ }^{8}$ In Africa, the total number of individuals with VI decreased slightly from 26.8 million in 2002 to 26.3 million in 2010.8 The observed decrease in the prevalence of VI globally and in Africa may be attributed to the achievements of the

TABLE 1: The International Classification of Diseases, 10th revision classification of visual impairment.

\begin{tabular}{lll}
\hline Category & \multicolumn{2}{c}{ Presenting distance visual acuity } \\
\cline { 2 - 3 } & Worse than & Equal to or better than \\
\hline O Mild or no visual & - & $6 / 18$ \\
& - & $3 / 10(0.3)$ \\
1 Moderate visual & - & $20 / 70$ \\
impairment & $6 / 18$ & $6 / 60$ \\
& $3 / 10(0.3)$ & $1 / 10(0.1)$ \\
2 Severe visual & $20 / 70$ & $20 / 200$ \\
impairment & $6 / 60$ & $3 / 60$ \\
& $1 / 10(0.1)$ & $1 / 20(0.05)$ \\
3 Blindness & $20 / 200$ & $20 / 400$ \\
& $3 / 60$ & $1 / 60 *$ \\
& $1 / 20(0.05)$ & $1 / 50(0.02)$ \\
4 Blindness & $20 / 400$ & $5 / 300(20 / 1200)$ \\
& $1 / 60 *$ & Light perception \\
& $1 / 50(0.02)$ & - \\
5 Blindness & $5 / 300(20 / 1200)$ & - \\
9 & No light perception & - \\
\hline & Undetermined or & - \\
\hline unspecified &
\end{tabular}

Source: World Health Organization. International statistical classification of diseases and related health problems 10th revision (ICD-10) [homepage on the Internet]. 2016 [cited 2017 Jan 16]. Available from: http://apps.who.int/classifications/icd10/browse/2015/en\#/H54

*, or counts fingers (CF) at 1 metre
VISION 2020: Right to Sight initiative by the WHO and the International Agency for the Prevention of Blindness (IAPB) that was implemented in $1999 .{ }^{15}$ Some of these achievements include a fivefold increase in the number of cataract operations performed in India, decrease in blindness because of trachoma and onchocerciasis, and reduction in childhood blindness as a result of vitamin A supplementation, immunisation against measles, and increased focus on retinopathy of prematurity. ${ }^{15}$ Furthermore, there has been profound advancement in providing spectacles to poor communities, thereby reducing VI caused by uncorrected refractive error. ${ }^{15}$

In terms of the levels of VI, the number of individuals with moderate and severe VI worldwide decreased from 269 million in 2004 to 246 million in 2010..$^{8,9,14}$ In addition, globally it is estimated that there are 17.5 million children aged 0-14 years with moderate and severe VI. ${ }^{8}$ Specifically in South Africa, the prevalence of individuals with moderate and severe VI decreased from 2.3\% (660 405 of 47.8 million) in 2005 to $2.0 \%$ (662 472 of 50.1 million) in $2010 .{ }^{16}$ However, there is a paucity of data available on VI in children and adolescents (aged 0-14 years) in South Africa. Of the global estimate of 1.4 million blind children, 1 million are found in Asia while 300000 are found in Africa. ${ }^{4}$

\section{Causes of visual impairment}

The causes of VI differ significantly between regions, with the prevalence of cataract being lowest and macular degeneration being greatest in high-income regions. ${ }^{17}$ Table $3^{7,8,9,10,17,18,19,20,21}$ summarises studies that have reported on the distribution of the major causes of VI. Globally, the leading causes of blindness and moderate and severe VI include uncorrected refractive error, cataract and macular degeneration. $., 8,9,17$ Bourne et al. ${ }^{17}$ further reported that the magnitude of individuals affected by blindness and moderate and severe VI caused by uncorrected refractive error increased from 6.3 million and 88.0 million in 1990 to 6.8 million and 101.2 million in 2010 , respectively.

In Africa, the main causes of moderate and severe VI in adults are cataracts and diseases affecting the cornea and retina. ${ }^{4,7}$ In Sub-Saharan Africa, the prevalence of cataracts causing VI

TABLE 2: Summary of studies reporting on the overall prevalence of visual impairment and its different levels.

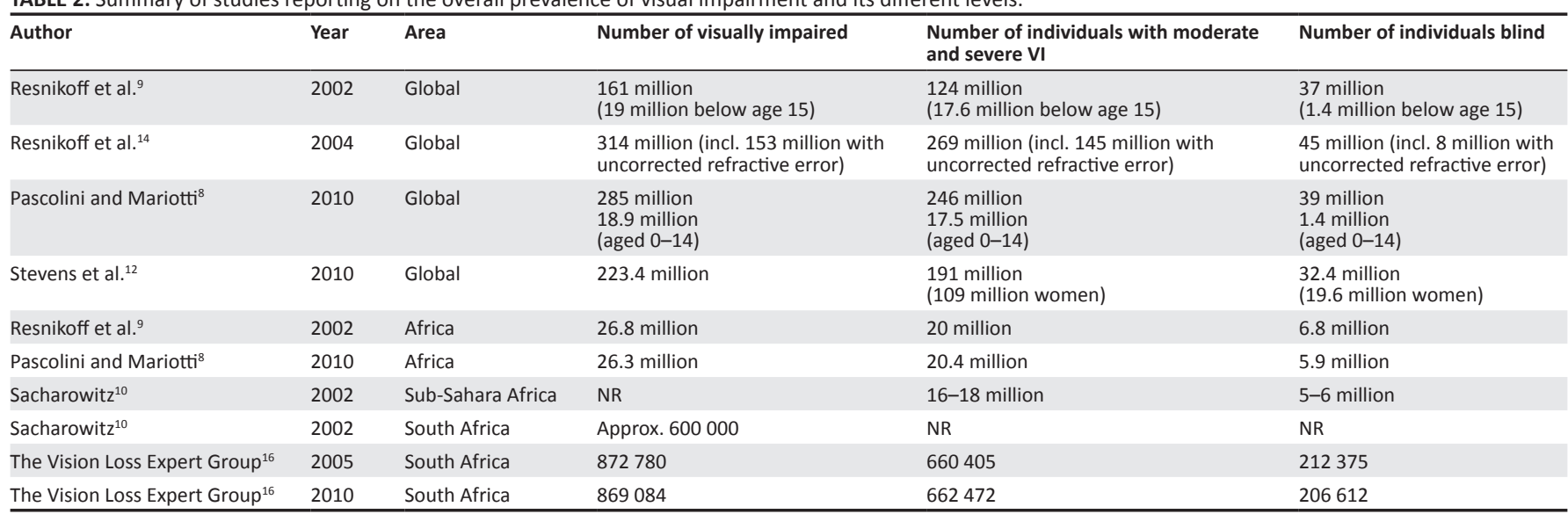

NR, not reported; VI, visual impairment. 
TABLE 3: Summary of studies reporting on the major causes of visual impairment.

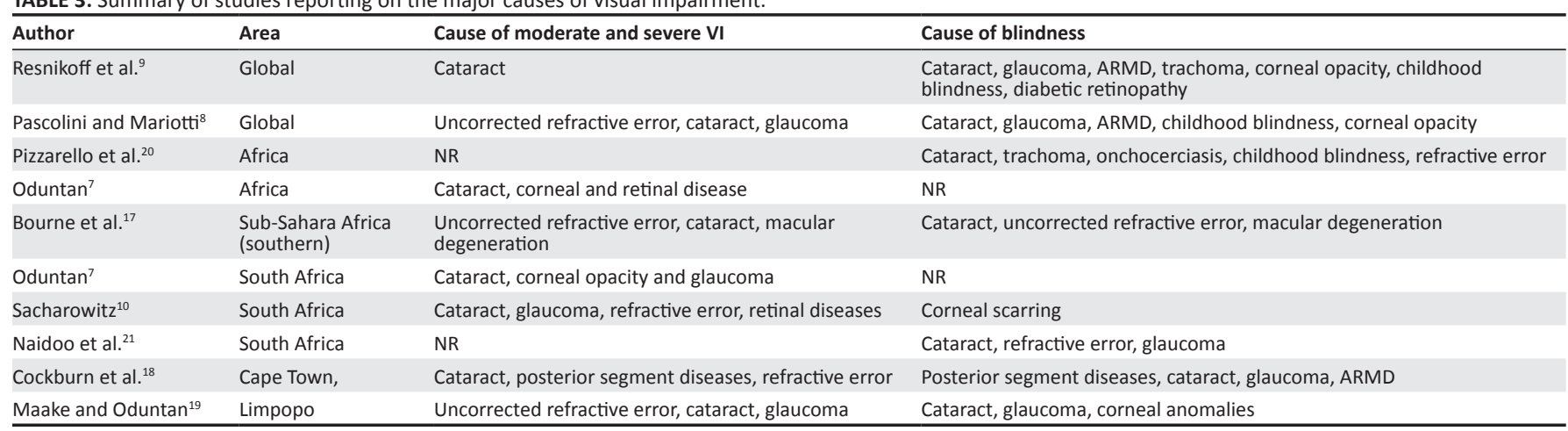

ARMD, Age-Related Macular Degeneration; NR, not reported; VI, visual impairment.

declined from $24.2 \%$ in 1990 to $17.8 \%$ in 2010 ; however, the prevalence of macular degeneration and glaucoma increased from $2.8 \%$ and $1.5 \%$ in 1990 to $4.8 \%$ and $2.6 \%$ in 2010, respectively. ${ }^{17}$ Specifically in South Africa, the main causes of moderate and severe VI include cataract, corneal opacity, glaucoma, refractive error and retinal diseases such as retinitis pigmentosa, Stargardt's disease, Usher's syndrome and Leber's Congenital Amaurosis. ${ }^{7,10}$ Recent studies undertaken in South Africa confirmed that cataract, uncorrected refractive error, posterior segment diseases (optic atrophy, trauma and macular hole) and glaucoma were the main causes of moderate and severe VI. ${ }^{18,19}$

Even though $65 \%$ of individuals with VI are older than 50 years, childhood blindness and VI remain a major concern because of the expected number of years to be lived. ${ }^{22}$ Of the 1.4 million children that are blind, a quarter is as a result of retinal diseases while $20 \%$ are because of corneal pathology. ${ }^{23}$ Cataract and glaucoma account for $13 \%$ and $6 \%$ of blindness in children, respectively. ${ }^{23}$ Globally, the main cause of moderate and severe VI in children aged 5-15 years is uncorrected refractive error. ${ }^{4}$ Corneal scarring accounts for between $25 \%$ and $50 \%$ of the VI reported in rural parts of Africa and Asia. ${ }^{23}$ In South Africa, the chief causes of childhood blindness include retinitis pigmentosa, albinism, cataract, glaucoma, nutritional causes, infections and inherited genetic disorders (other than retinitis pigmentosa and albinism) ${ }^{7}$

\section{Implications of visual impairment}

Visual impairment has severe consequences, more especially in developing countries. Its debilitating effects decrease the ability of affected individuals to function independently and may negatively impact daily living and quality of life. ${ }^{24}$ Most of the information about the world is achieved through the sense of vision as it is fundamental to learning and integrating information from the other sensory organs. ${ }^{25,26,27}$ Approximately $80 \%$ of learning occurs through vision. Thus, if VI is present at birth or develops shortly afterwards, it may negatively impact development. As a result, children with VI are developmentally delayed in gross and fine motor skills in addition to visual perception. ${ }^{28}$ Furthermore, approximately $90 \%$ of children with VI are deprived of an education because of socioeconomic and physical barriers including discrimination and stigmatisation, limited accessible schools and the inability to cope with the impairment. ${ }^{4,29}$

The physical, social and psychological well-being of children and adolescents are also negatively affected. ${ }^{30}$ It has been reported that children and adolescents with VI experienced reduced quality of life when compared to age-matched children and adolescents without VI. ${ }^{31} \mathrm{VI}$ also contributes to the socioeconomic burden on society as a result of a loss in education, career opportunities and economic gain for individuals with VI and their families. ${ }^{14,32}$

\section{Rehabilitation in visual impairment}

The functional ability of an individual with VI is not determined solely by the magnitude of vision loss. In addition to the physiology of the eye, other physical, psychological and social factors also influence daily living. Individuals with VI experience more symptoms of depression than those without VI. ${ }^{33}$ The combination of social, functional and psychological disabilities related to VI result in an overall reduction in quality of life. ${ }^{33}$ As a result, rehabilitation of an individual with VI requires a holistic approach that considers social, economic and psychological needs in addition to their visual needs. ${ }^{34}$ An ideal interdisciplinary team of health care professionals that can provide such an approach would include, among others, an optometrist, ophthalmologist, psychologist, audiologist, occupational therapist, orientation and mobility instructor and physiotherapist. ${ }^{34}$

The rehabilitation of children and adolescents with VI aims to increase their functionality and independence, aid in their education and improve their social interaction. It has been reported that proper management of individuals with VI can provide the same quality of life as that of normally sighted individuals. $^{2}$ Rehabilitation services should be made available, accessible and affordable particularly in developing countries. Early intervention provides effective visual rehabilitation and is vital in reducing the incidence and impact of VI. The perspective of the child with VI is vital in their rehabilitation as their views do not always correspond with the views of their parents or even that of the health care professionals. ${ }^{30}$ Significant gender differences exist regarding access to rehabilitation for individuals with VI. Even though more women are blind or have VI, only a minority seek 
rehabilitation and/or low vision services. ${ }^{35}$ This warrants the need for vision screening and awareness programmes targeting women, more especially in developing areas.

\section{Conclusion}

Visual impairment remains a global concern that is likely to escalate with prolonged life expectancies. Approximately $90 \%$ of individuals with VI live in developing countries because of poor access to health care services. ${ }^{4,7}$ There has been an overall decline in the number of individuals with VI from 314 million to 285 million in 2010, which may be attributed to the achievements of the VISION 2020: Right to Sight initiative. ${ }^{8,14,15}$ Women are at higher risk of VI than men; however, this gender disparity was lowest in Sub-Saharan Africa. ${ }^{4,12}$ The implications of childhood blindness and VI may be more significant because of greater life expectancies, ${ }^{22}$ thus contributing to the socioeconomic burden on society. ${ }^{14}$ As a result, rehabilitation of individuals with VI requires a holistic approach that is readily available, accessible and affordable, particularly in developing countries. ${ }^{34}$

\section{Acknowledgements Competing interests}

The authors declare that they have no financial or personal relationships which may have inappropriately influenced them in writing this article.

\section{Authors' contributions}

This article forms part of a Master of Optometry research study (BE $457 / 16$ ) being undertaken by S.N. with N.R. as the supervisor.

\section{References}

1. DeCarlo DK, Woo S, Woo GC. Patients with low vision. In: Benjamin WJ, editor. Borish's clinical refraction. 2nd ed. Philadelphia: Elsevier; 2006, p. 1591-1618.

2. Kavitha V, Manumali MS, Praveen K, Heralgi MM. Low vision aid-A ray of hope for irreversible visual loss in the pediatric age group. Taiwan J Ophthalmol. 2015;5(2):63-67. https://doi.org/10.1016/j.tjo.2015.02.002

3. Corn AL, Lusk KE. Perspectives on low vision. In: Corn AL, Erin JN, editors. Foundations of low vision: Clinical and functional perspectives. 2nd ed. New York: AFB Press; 2010, p. 3-34.

4. World Health Organization. Global initiative for the elimination of avoidable blindness - Action plan 2006-2011. Geneva: World Health Organization; 2007 [cited 2017 Jan 07] p. 18. Available from: http://www.who.int/iris/handle/ $10665 / 43754$

5. WHO Programme for the Prevention of Blindness. Management of low vision in children: Report of a WHO consultation, Bangkok, 23-24 July 1992. Geneva: World Health Organization; 1993. p. 3.

6. World Health Organization. International statistical classification of diseases and related health problems 10th revision (ICD-10) [homepage on the Internet]. 2016 [cited 2017 Jan 16]. Available from: http://apps.who.int/classifications/icd10/ browse/2015/en\#/H54

7. Oduntan AO. Prevalence and causes of low vision and blindness worldwide. S Afr Optom. 2005;64(2):44-54. https://doi.org/10.4102/aveh.v64i2.214

8. Pascolini D, Mariotti SP. Global estimates of visual impairment: 2010. Br J Ophthalmol. 2012;96(5):614-618. https://doi.org/10.1136/bjophthalmol-2011-300539
9. Resnikoff S, Pascolini D, Etya'ale D, et al. Global data on visual impairment in the year 2002. Bull World Health Organ. 2004;82(11):844-551.

10. Sacharowitz HS. Visual impairments in South Africa: Achievements and challenges. S Afr Optom. 2005;64(4):139-149. https://doi.org/10.4102/aveh.v64i4.239

11. Watkins RD. The management of global blindness. Clin Exp Optom. 2001; 84(3):104-112. https://doi.org/10.1111/j.1444-0938.2001.tb04953.x

12. Stevens GA, White RA, Flaxman SR, et al. Global prevalence of vision impairment and blindness magnitude and temporal trends, 1990-2010. Ophthalmology. 2013;120(12):2377-2384. https://doi.org/10.1016/j.ophtha.2013.05.025

13. Murthy $G$, Johnson $G$. Prevalence, incidence and distribution of visual impairment Epidemiol Eye Dis. 2012;3-61. https://doi.org/10.1142/9781848166271_0001

14. Resnikoff S, Pascolini D, Mariotti SP, Pokharel GP. Global magnitude of visual impairment caused by uncorrected refractive errors in 2004. Bull World Health Organ. 2008;86(1):63-70. https://doi.org/10.2471/BLT.07.041210

15. Ackland P. Ten years to VISION 2020: How are we doing? Clin Vis Sci. 2010; 23(74):54-55.

16. The Vision Loss Expert Group. Global Vision Database Maps • IAPB Vision Atlas [homepage on the Internet]. 2016 [cited 2017 Mar 5]. Available from: http://atlas. iapb.org/gvd-maps/\#by-condition

17. Bourne RRA, Stevens GA, White RA, et al. Causes of vision loss worldwide, 1990-2010: A systematic analysis. Lancet Glob Heal. 2013;1(6):339-349. https:// doi.org/10.1016/S2214-109X(13)70113-X

18. Cockburn N, Steven D, Lecuona K, et al. Prevalence, causes and socio-economic determinants of vision loss in Cape Town, South Africa. PLoS One. 2012;7(2):1-7. https://doi.org/10.1371/journal.pone.0030718

19. Maake MM, Oduntan OA. Prevalence and causes of visual impairment in patients seen at Nkhensani Hospital Eye Clinic, South Africa. African J Prim Heal Care Fam Med. 2015;7(1):6-11. https://doi.org/10.4102/phcfm.v7i1.728

20. Pizzarello L, Abiose A, Ffytche T, et al. Vision 2020: The right to sight. Arch Ophthalmol. 2004;122(April):615-620. https://doi.org/10.1001/archopht.122.4.615

21. Naidoo KS, Sweeney D, Jaggernath J, Holden B. A population-based study of visual impairment in the Lower Tugela health district in KZN, SA. S Afr Optom. 2013;72(3):110-118. https://doi.org/10.4102/aveh.v72i3.284

22. World Health Organization. Visual impairment and blindness fact sheet [homepage on the Internet]. World Health Organization; 2014 [cited 2017 Jan 17]. Available from: http://www.who.int/mediacentre/factsheets/fs282/en/

23. Gilbert C, Foster A. Blindness in children: Control priorities and research opportunities. Br J Ophthalmol. 2001;85(9):1025-1027. https://doi.org/10.1136/ bjo.85.9.1025

24. West SK, Rubin GS, Broman AT, Muñoz B, Bandeen-Roche K, Turano K. How does visual impairment affect performance on tasks of everyday life. Arch Ophthalmol. 2002;120(6):774-780. https://doi.org/10.1001/archopht.120.6.774

25. American Optometric Association. School-aged vision: 6 to 18 years of age [homepage on the Internet]. 2006 [cited 2017 Jan 7]. Available from: http://www. aoa.org/patients-and-public/good-vision-throughout-life/childrens-vision/ school-aged-vision-6-to-18-years-of-age?sso=y

26. Khadka J, Ryan B, Margrain TH, Woodhouse JM, Davies N. Listening to voices of children with a visual impairment: A focus group study. Br J Vis Impair. 2012;30(3):182-196. https://doi.org/10.1177/0264619612453105

27. Raj $L$. How to assess and plan for the management of visually challenged children in the context of multiple different-abilities. Community Eye Heal. 2007; 20(62):91-94

28. Abdullah MS, Jani J, Abdullah N. A preliminary study to compare motor skills ability among people with albinism in Malaysia and Australia. J Pendidik Bitara. 2012;5:1-12.

29. Holden BA. Blindness and poverty: A tragic combination. Clin Exp Optom 2007;90(6):401-403. https://doi.org/10.1111/j.1444-0938.2007.00217.x

30. Rainey L, Elsman EBM, Van Nispen RMA, Van Leeuwen LM, Van Rens GHMB. Comprehending the impact of low vision on the lives of children and adolescents: A qualitative approach. Qual Life Res. 2016;25:2633-2643. https://doi.org/ 10.1007/s11136-016-1292-8

31. Chadha RK, Subramanian A. The effect of visual impairment on quality of life of children aged 3-16 years. Br J Ophthalmol. 2010;95(5):642-645. https://doi. org/10.1136/bjo.2010.182386

32. Khanna R, Raman U, Rao GN. Blindness and poverty in India: The way forward. Clin Exp Optom. 2007;90(6):406-414. https://doi.org/10.1111/j.1444-0938.2007.00199.x

33. Binns AM, Bunce $C$, Dickinson $C$, et al. How effective is low vision service provision? A systematic review. Surv Ophthalmol. 2012;57(1):34-65. https://doi.org/ 10.1016/j.survophthal.2011.06.006

34. Oduntan OA. A review of rehabilitation of low vision patients. S Afr Optom. 2008;67(4):166-175. https://doi.org/10.4102/aveh.v68i4.197

35. Uprety S, Khanal S, Morjaria P, Puri LR. Profile of paediatric low vision population: A retrospective study from Nepal. Clin Exp Optom. 2016;99(1):61-65. https://doi. org/10.1111/cxo.12314 